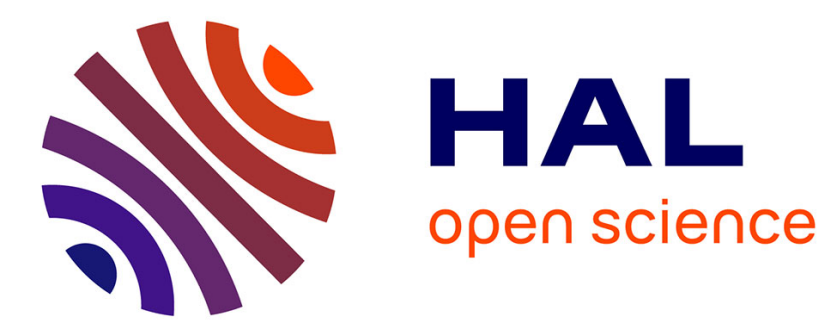

\title{
VEGF-A Splice Variants: Do They Play a Role in Tumor Responses to Anti-Angiogenic Therapies?
}

Béatrice Eymin, Asma Boudria, Cherine Abou-Fayçal

\section{To cite this version:}

Béatrice Eymin, Asma Boudria, Cherine Abou-Fayçal. VEGF-A Splice Variants: Do They Play a Role in Tumor Responses to Anti-Angiogenic Therapies?. Molecular Mechanisms of Angiogenesis, pp 421-442, 2014, 10.1007/978-2-8178-0466-8_21 . inserm-02345395

\section{HAL Id: inserm-02345395 https://www.hal.inserm.fr/inserm-02345395}

Submitted on 4 Nov 2019

HAL is a multi-disciplinary open access archive for the deposit and dissemination of scientific research documents, whether they are published or not. The documents may come from teaching and research institutions in France or abroad, or from public or private research centers.
L'archive ouverte pluridisciplinaire HAL, est destinée au dépôt et à la diffusion de documents scientifiques de niveau recherche, publiés ou non, émanant des établissements d'enseignement et de recherche français ou étrangers, des laboratoires publics ou privés. 


\title{
VEGF-A Splice Variants: Do They Play a Role in Tumor Responses to Anti-Angiogenic Therapies?
}

\author{
Beatrice Eymin, Asma Boudria and Cherine Abou-Faycal \\ INSERM U823, Team 2 Molecular Basis of Lung Cancer Progression \\ Institut Albert Bonniot, Grenoble, France \\ e-mail: beatrice.eymin@ujf-grenoble.fr
}

\begin{abstract}
It has been known for two decades that $V E G F-A$ encodes several VEGF-A splice variants, which are termed $\mathrm{VEGF}_{\mathrm{xxx}}$, according to the total number of amino acids in the mature protein. To date, nine $\mathrm{VEGF}_{\mathrm{xxx}}$ isoforms have been described, displaying different biodistribution and pro-angiogenic activity. Adding another level of complexity to VEGF-A biology, a new family of VEGF-A isoforms, termed $\mathrm{VEGF}_{\mathrm{xxx}} \mathrm{b}$, which exert anti-angiogenic functions was discovered in 2002 and only differ from VEGF $_{x x x}$ polypeptides with regard to their C-terminal six amino acids. Therefore, reminiscent of what is observed, for instance, during apoptosis, the alternative splicing of $V E G F-A$ pre-mRNA generates two types of isoforms with antagonistic biological functions. As anti-angiogenic therapies target both the $V_{E G F} F_{x x}$ and $V_{E G F}$ xx $b$ families, $V E G F-A$ pre-mRNA splicing may therefore impact tumor responses to these therapies. Consistently, recent clinical studies have highlighted VEGF-A splice variants as predictive biomarkers in response to bevacizumab. Hence, identification of the upstream signaling pathways that control $V E G F-A$ pre-mRNA splicing, better characterization of the specific biological functions played by each VEGF-A splice variant, and/or analysis of the impact of anti-angiogenic therapies on $V E G F-A$ pre-mRNA splicing are critical goals. The purpose of this chapter is to summarize the current knowledge in this field.
\end{abstract}




\subsection{Proteome Diversity Through Pre-mRNA Alternative Splicing: $V E G F-A$ Does Not Escape the Rule}

Deep-sequencing of the human transcriptome has provided evidence that up to $90 \%$ of human multi-exon genes undergo pre-mRNA alternative splicing (AS) (Pan et al. 2008), and the role of AS in both physiological and pathological processes, such as cancer, is now welldocumented. For instance, many splice variants have been found to be misregulated in cancers (David and Manley 2010), among them $V E G F$ - $A$-encoded splice variants.

\subsubsection{The VEGF $F_{x x x}$ Family}

\subsubsection{General Presentation}

The human $V E G F-A$ gene is located on chromosome 6 at $6 \mathrm{p} 21.3$ and spans $14 \mathrm{~kb}$, with eight exons separated by seven introns (Vincenti et al. 1996) (Fig. 6.1). Two years after its discovery, $V E G F-A$ was found to encode multiple protein isoforms through exonic alternative splicing (Houck et al. 1991). To date, nine human VEGF-A splice variants, termed VEGF $\mathrm{xxx}_{\mathrm{xx}}$ (where $\mathrm{xxx}$ represents the total number of amino acids in the mature protein after signal sequence cleavage), have been described: $\mathrm{VEGF}_{111}, \mathrm{VEGF}_{121}, \mathrm{VEGF}_{145}, \mathrm{VEGF}_{148}, \mathrm{VEGF}_{162}$, $\mathrm{VEGF}_{165}, \mathrm{VEGF}_{183}, \mathrm{VEGF}_{189}$, and $\mathrm{VEGF}_{206}$ (Ferrara 2004). At the structural level (Fig. 6.1), with the exception of $\mathrm{VEGF}_{111}$ (containing exons 1-4), all $\mathrm{VEGF}_{\mathrm{xxx}}$ isoforms contain exons 15 and differ only by the inclusion/exclusion of exon $6 \mathrm{a}, 6 \mathrm{~b}$, or 7 . Hence, $\mathrm{VEGF}_{189}$ lacks the residues encoded by exon $6 \mathrm{~b}, \mathrm{VEGF}_{165}$ those encoded by exon 6 , and $\mathrm{VEGF}_{121}$ those encoded by exons 6 and 7 . Exons $6 \mathrm{a}$ and 7 encode highly conserved sequences that are rich in basic residues that confer an affinity for heparin-containing proteoglycans (Fig. 6.2). Therefore, VEGF $_{121}$ is an acidic protein that does not bind heparin and is highly diffusible, whereas the VEGF 206, 189, 183, 162, and 145 isoforms tightly bind to the heparan sulfate that is present at the cell surface and extracellular matrix [ECM; (Houck et al. 1992)]. The VEGF 165 isoform displays an intermediate pattern, as it contains only 15 basic amino acids within the 44 residues encoded by exon 7 , and it is estimated that approximately $50-70 \%$ of the $\mathrm{VEGF}_{165}$ pool is anchored at the cell surface or ECM (Houck et al. 1992). The VEGF-A isoforms in the ECM constitute a reservoir of growth factor that can be slowly released after exposure to heparin, heparan sulfate, and heparinases or more rapidly mobilized by specific proteolytic enzymes, such as plasmin and urokinase-type plasminogen activator (uPA) (Plouet et al. 1997). Importantly, the loss of the heparin-binding domain after proteolytic cleavage reduces the mitogenic activity of VEGF-A (Keyt et al. 1996). Therefore, $V E G F-A$ pre-mRNA splicing controls both the biodistribution and bioactivity of VEGF-A, allowing the establishment of a gradient of VEGF-A during tumor angiogenesis, with the most diffusible isoform acting at distance to promote vascular recruitment, whereas the matrix-bound isoforms promote the local expansion of capillary beds (Grunstein et al. 2000).

All VEGF-A isoforms are secreted as antiparallel homodimers covalently linked by two disulfide bridges between Cys-51 and Cys-60 (Muller et al. 1997). At the structural level, all isoforms possess a dimerisation domain and a VEGFR1 or VEGFR2 binding domain (Fig. 6.2). However, the isoforms display different binding affinities for the VEGF receptors, VEGFR1 (Flt-1) and VEGFR2 (KDR/Flk-1), and for their co-receptors, neuropilin-1 (NRP1) and neuropilin-2 (NRP2) (Roskoski 2007). Hence, VEGF 165 binds to VEGFR1 and VEGFR2, whereas VEGF $_{189}$ preferentially binds to VEGFR1 unless cleaved by proteases. VEGF 121 exhibits a modestly reduced affinity for VEGFR1 and VEGFR2 in the presence of heparin 
when compared with $\mathrm{VEGF}_{165}$. Although all $\mathrm{VEGF}_{189}, \mathrm{VEGF}_{165}$, and $\mathrm{VEGF}_{121}$ isoforms are able to bind NRP1 (Delcombel et al. 2013), only VEGF $_{165}$ bridges the formation of VEGFR2/NRP1 ternary complexes (Soker et al. 2002), whereas VEGFR2 enhances the interaction between NRP1 and VEGF 165 only (Pan et al. 2007a). Therefore, as compared with the other $\mathrm{VEGF}_{\mathrm{xxx}}$ isoforms, $\mathrm{VEGF}_{165}$ displays optimal features in terms of biological potency. Indeed, $\mathrm{VEGF}_{165}$ is the only isoform that can fully rescue the tumorigenic phenotype in mouse VEGF-/- cells (Grunstein et al. 2000). Interestingly, matrix-bound VEGF 165 , but not soluble $\mathrm{VEGF}_{165}$, is able to trigger a sustained phosphorylation of VEGFR2 in endothelial cells, followed by a specific activation of the p38 MAPK pathway (Chen et al. 2010). These data suggest that $\mathrm{VEGF}_{\mathrm{xxx}}$ isoforms transactivate specific downstream VEGFR-dependent signaling pathways depending on their ECM-binding ability.

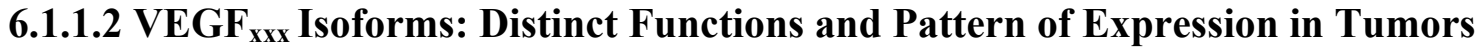

As determined by the cDNA analysis of a variety of cell types and tissues and tumor specimens, most VEGF-producing cells appear to preferentially to express $V E G F_{121}, V E G F_{165}$ and $V E G F_{189}$ mRNAs, with $V E G F_{165}$ being the predominant isoform. $V E G F_{121} \mathrm{mRNA}$ is abundant in lung and kidney, and $V E G F_{189} \mathrm{mRNA}$ is highly expressed in cardiac and vascular tissues, albeit to a lesser extent than $V E G F_{165}$ and $V E G F_{121}$ (Zygalaki et al. 2008). $V E G F_{189}$ mRNA is preferentially expressed under conditions of increased stretch-induced cell tension and is thought to play a role in vascularization during bone repair (Faure et al. 2008). $V E G F_{183}$ also has a wide tissue distribution and may have avoided earlier detection through confusion with $V_{E G F} 189$ (Jingjing et al. 1999). By contrast, $V E G F_{145}$ and $V E G F_{206}$ mRNAs are rarely expressed and are seemingly restricted to cells of placental origin (Cheung et al. 1995).

In tumors, RT-PCR or RT-QPCR analyses have further revealed differential patterns of $\mathrm{VEGF}_{\mathrm{xxx}}$ expression and have correlated this pattern with clinico-pathological features. In lung and colon carcinomas, $V E G F_{165}$ and $V E G F_{121}$ mRNAs appear to be the most predominant transcripts (Zygalaki et al. 2007). $V E G F_{165}$ mRNA expression in many tumor types has been associated with progression, invasion and metastasis, microvessel density, decreased survival rate, and a poor prognosis. In colon, renal cell, and lung carcinomas, the expression of $V E G F_{189} \mathrm{mRNA}$ was associated with a worse prognosis (Ohta et al. 1996), and only $V E G F_{189}$ mRNA expression was found to be an independent prognostic indicator in a series of 130 Non Small Cell Lung Carcinomas (NSCLCs) (Matsuyama et al. 2009). VEGF 189 was also found to be necessary for the growth of NSCLC xenografts in vivo, with VEGF $189^{-}$ overexpressing tumors being larger and displaying higher vessel perfusion and permeability than those overexpressing either $\mathrm{VEGF}_{121}$ or $\mathrm{VEGF}_{165}$ (Yuan et al. 2001). However, in lung cancer, high levels of $V E G F_{121}$ mRNA have also been associated with a poor prognosis and lymph node metastasis (Oshika et al. 1998), and $V_{E G F}$ was found to promote lymphangiogenesis via the secretion of VEGF-C (Kawai et al. 2008). In addition, expression of $V E G F_{121}$ mRNA was associated with the tumor progression of bladder and renal cell carcinoma (Li et al. 2000; Ljungberg et al. 2003) and with a worse prognosis in acute myeloid leukemia (Mourah et al. 2009), and the $\mathrm{VEGF}_{121}$ isoform was found to be the most tumorigenic in prostate and breast cancers (Catena et al. 2007). In 2007, it was reported that VEGF $_{111}$ mRNA was expressed in various tumor cell lines following treatment with such genotoxic agents as UV-B, camptothecin, and mitomycin C (Mineur et al. 2007).

Altogether, these data demonstrate that $V E G F-A$ pre-mRNA splicing likely contributes to tumorigenesis by providing an another way to finely regulate VEGF-A bioactivity in addition 
to the activation of $V E G F-A$ transcription. Such a notion is fully consistent with the data of Tozer and colleagues, which provided evidence that mouse fibrosarcoma cells that express only a single isoform of $\mathrm{VEGF}_{\mathrm{xxx}}$ produce tumors with different vascularization patterns, vessel wall structure, and barrier function (Tozer et al. 2008).

\subsubsection{The VEGF $F_{x x x}$ F Family: Six Amino Acids that Make the Difference}

\subsubsection{General Presentation}

In 2002, a new family of VEGF-A splice variants, termed VEGF $_{x x x} b$, was discovered (Bates et al. 2002). $V_{E G F} F_{x x x} b$ splice variants share $94-98 \%$ homology with $V_{E G F} F_{x x}$ and result from the use of an alternative 3' splice acceptor site in the final exon 8 of $V E G F-A$ (Fig. 6.1). Hence, the use of a proximal splice site (PSS) in exon 8 leads to the inclusion of exon 8a and generates the $\mathrm{VEGF}_{\mathrm{xxx}}$ family, whereas the use of a distal splice site (DSS) located 66 nucleotides further downstream from PSS allows the inclusion of exon $8 \mathrm{~b}$ and the generation of $\mathrm{VEGF}_{\mathrm{xxx}} \mathrm{b}$ transcripts. At the protein level, $\mathrm{VEGF}_{\mathrm{xxx}}$ and $\mathrm{VEGF}_{\mathrm{xxx}} \mathrm{b}$ isoforms display the same lengths and amino acids sequences and differ only at the level of their C-terminal six amino acids. Indeed, exon $8 \mathrm{a}$ in $\mathrm{VEGF}_{\mathrm{xxx}}$ mRNAs encodes a CDKPRR sequence, whereas exon $8 \mathrm{~b}$ in $\mathrm{VEGF}_{\mathrm{xxx}} \mathrm{b}$ transcripts encodes an SLTRKD sequence (Ladomery et al. 2007). This distinct C-terminal extremity strongly affects the VEGF-A tertiary structure (Cui et al. 2004), as the Cys-160 that forms a disulfide bond with Cys-146 in exon 7 is replaced by an aspartic acid residue. In addition, the two highly charged arginine residues of the $\mathrm{VEGF}_{\mathrm{xxx}}$ proteins are replaced by a lysine and aspartic acid in the $\mathrm{VEGF}_{\mathrm{xxx}} \mathrm{b}$ proteins, with a substitution of a proline by an arginine. As a consequence, the $\mathrm{VEGF}_{\mathrm{xxx}} \mathrm{b}$ isoforms retain both the VEGF tyrosine kinase receptor binding and dimerization domains but do not bind neuropilins and are not able to fully activate VEGFR-dependent signaling pathways (Cebe Suarez et al. 2006; Kawamura et al. 2008; Delcombel et al. 2013). Indeed, $V_{E G F}{ }_{165}$ b does not exert its effect at full rotation on VEGFR2, which results in the rapid blockage of the ATP binding site, leading to transient and non-efficient VEGFR2 auto-phosphorylation (Harper and Bates 2008). Thus, although $\mathrm{VEGF}_{165} \mathrm{~b}$ is able to stimulate endothelial cell proliferation and subsequent ERK activation under certain conditions, this occurs with less potency than with VEGF 165 (Catena et al. 2010). In addition, unlike $V_{E G F}$ 165, which induces VEGFR2 internalization and recycling to the plasma membrane through Rab11 vesicles by a mechanism involving NRP1, VEGF $_{165} \mathrm{~b}$ promotes the accumulation of phospho-VEGFR2 in Rab7 vesicles, which is indicative of receptor degradation (Ballmer-Hofer et al. 2011). At the biological level, in in vitro endothelial proliferation and migration assays, ex vivo isolated resistance vessel myographs, and in vivo neo-vascular and tumor growth models, $V_{E G F}{ }_{165} \mathrm{~b}$ acts as a dominant negative isoform that specifically competes with and inhibits $\mathrm{VEGF}_{165}$ effects on endothelial cell proliferation, migration, and vasodilatation, thereby inhibiting angiogenesis and tumor growth (Bates et al. 2002; Woolard et al. 2004; Rennel et al. 2008). VEGF ${ }_{121}$ b also inhibits the migration of endothelial cells and reduces xenografted tumor growth through a direct effect on endothelial cells (Rennel et al. 2009). Interestingly, $\mathrm{VEGF}_{165} \mathrm{~b}$ failed to bind heparin despite possessing exon 7 (Delcombel et al. 2013), implicating exon 8a or an inhibitory

function of exon $8 \mathrm{~b}$ in this interaction. Therefore, as compared with $\mathrm{VEGF}_{\mathrm{xxx}}, \mathrm{VEGF}_{\mathrm{xxx}} \mathrm{b}$ isoforms could also possess distinct bioavailability. 


\subsubsection{VEGF Vxx $_{\mathrm{xx}}$ Isoforms: Do They Exhibit a Differential Pattern of Expression in Tumors?}

$V E G F_{165} b$ mRNA was the first $V E G F_{x x x} b$ mRNA identified by RT-PCR in kidney cortex tissue (Bates et al. 2002). Subsequently, $V E G F_{121} b$ (Rennel et al. 2009), $V E G F_{145} b$ (Perrin et al. 2005), and $V E G F_{189} b$ mRNAs (Miller-Kasprzak and Jagodzinski 2008) were identified in various human tissues. Indeed, $\mathrm{VEGF}_{\mathrm{xxx}} \mathrm{b}$ isoforms are thought to form over $50 \%$ of the total VEGF-A protein in normal, non-angiogenic tissues, such as dorsal root ganglia (71\%), lung $(82 \%)$, colon (>95\%), skin (>95\%) (Qiu et al. 2009), and vitreous (66\%) (Perrin et al. 2005). By contrast, $\mathrm{VEGF}_{\mathrm{xxx}} \mathrm{b}$ represents a small proportion of total VEGF-A in placenta $(1.4 \%)$ (Bates et al. 2006). Importantly, although $\mathrm{VEGF}_{\mathrm{xxx}}$ isoforms are overexpressed in many tumor types, the $\mathrm{VEGF}_{\mathrm{xxx}} \mathrm{b}$ isoforms appear to be mainly downregulated in several cancers, including melanoma (Pritchard-Jones et al. 2007), prostate (Woolard et al. 2004), colon (Varey et al. 2008), kidney (Bates et al. 2002), and Wilm's (Amin et al. 2011) carcinomas. In colorectal tumors, the downregulation of $\mathrm{VEGF}_{165} \mathrm{~b}$ was associated with advanced stages, vascular invasion, and lymph node metastases (Diaz et al. 2008), and the absence of $\mathrm{VEGF}_{\mathrm{xxx}} \mathrm{b}$ expression was found to predict metastatic spread in melanoma patients (PritchardJones et al. 2007). Moreover, $\mathrm{VEGF}_{165} \mathrm{~b}$ expression was downregulated as compared with $\mathrm{VEGF}_{165}$ in neuroblastoma, and $\mathrm{rhVEGF}_{165} \mathrm{~b}$ was found to reduce neuroblastoma tumor growth rate in established xenografts (Peiris-Pages et al. 2010). Therefore, a switch between the $\mathrm{VEGF}_{\mathrm{xxx}}$ and $\mathrm{VEGF}_{\mathrm{xxx}} \mathrm{b}$ isoforms in favor of $\mathrm{VEGF}_{\mathrm{xxx}}$ exists in human tumors. Regardless, the persistence of $\mathrm{VEGF}_{\mathrm{xxx}} \mathrm{b}$ expression, together with $\mathrm{VEGF}_{\mathrm{xxx}}$, has also been reported in tumors. This is indeed the case in $70 \%$ of clear renal cell carcinoma (Grepin et al. 2012) and in breast cancers in which the $\mathrm{VEGF}_{\mathrm{xxx}} \mathrm{b}$ isoforms are upregulated compared to nonmalignant breast tissues (Catena et al. 2010). VEGF $_{165}$ b expression was also detected in stromal cells surrounding colorectal cancers and correlated with lower microvessel density (Tayama et al. 2011). Moreover, Bates and colleagues recently showed that a differential pattern of $\mathrm{VEGF}_{165} \mathrm{~b}$ protein expression exists in colon carcinoma, with tumors displaying low or high levels as compared with normal tissues (Bates et al. 2012). Accordingly, we observed that approximately $35 \%$ and $15 \%$ of NSCLCs display a low or high level of $\mathrm{VEGF}_{165} \mathrm{~b}$ protein expression, respectively, as compared with normal lung tissues (Boudria et al in preparation). More interestingly, we found a significant association between high levels of $\mathrm{VEGF}_{165} \mathrm{~b}$ and lymph node metastases in NSCLC. Thus, the role of $\mathrm{VEGF}_{\mathrm{xxx}} \mathrm{b}$ isoforms during tumorigenesis might be more complex than previously imagined.

\subsubsection{Analysis of $V E G F-A$ Splice Isoforms in Tumors: What We Should Keep in Mind}

As shown above, the analysis of distinct $\mathrm{VEGF}_{\mathrm{xxx}}$ isoforms in human tumors has been mainly performed by RT-PCR or RT-QPCR using primers specifically designed to amplify each $V E G F_{x x x}$ splice variant. However, in the vast majority of these studies, these primers were later shown to also co-amplify $V E G F_{x x x} b$ mRNAs. The same is true regarding the analysis of the $\mathrm{VEGF}_{\mathrm{xxx}}$ protein isoforms. Indeed, the antibodies used in the vast majority of in situ studies are pan-VEGF antibodies that recognize all VEGF-A isoforms, including $\mathrm{VEGF}_{\mathrm{xxx}} \mathrm{b}$ isoforms. Hence, the commercial antibodies previously thought to specifically target $\mathrm{VEGF}_{\mathrm{xxx}}$ isoforms were later found to cross-react with $\operatorname{rhVEGF}_{\mathrm{xxx}} \mathrm{b}$ proteins. To date, there is no tool for the specific detection of $\mathrm{VEGF}_{\mathrm{xxx}}$ protein isoforms by western blotting, as the use of a pan-VEGF antibody will allow the discrimination among $\mathrm{VEGF}_{121}, \mathrm{VEGF}_{165}$, and VEGF 189 but not between the $\mathrm{VEGF}_{\mathrm{xxx}}$ and $\mathrm{VEGF}_{\mathrm{xxx}} \mathrm{b}$ isoforms. Nonetheless, mouse monoclonal antibodies directed against the C-terminal nine amino acids of $\mathrm{VEGF}_{165} \mathrm{~b}$ (CTRSLTRKD) have been developed; one (MVRL56/1) now commercially available, exhibits specificity for 
the $\mathrm{VEGF}_{165} \mathrm{~b}$ isoform versus $\mathrm{VEGF}_{165}$ and does not cross-react with $\mathrm{VEGF}_{165}$ or $\mathrm{VEGF}_{121}$ recombinant proteins (Woolard et al. 2004). Therefore, until tools allowing the specific detection of $\mathrm{VEGF}_{\mathrm{xxx}}$ isoforms become available, a concomitant analysis of both total VEGFA (using a pan-VEGF-A antibody) and $V_{E G F}$ b (using the specific MVRL56/1 anti$\mathrm{VEGF}_{\mathrm{xxx}} \mathrm{b}$ antibody) proteins should be performed before drawing conclusions regarding the status of VEGF-A in tumors. In addition, because $V E G F-A$ is regulated at multiple posttranscriptional levels in addition to pre-mRNA splicing and it is not known whether the mRNA and protein levels are strictly correlated, concomitant analyses of both $\mathrm{VEGF}_{\mathrm{xxx}} / \mathrm{VEGF}_{\mathrm{xxx}} \mathrm{b} \mathrm{mRNA}$ and protein levels should also be performed.

\subsubsection{Molecular Mechanisms Regulating VEGF-A Pre-mRNA Splicing}

Several transcription factors, such as hypoxia-inducible factor 1 (HIF-1), inflammatory cytokines, growth factors, or oncogenes, have been identified as upstream transcriptional activators of $V E G F-A$ (Ferrara 2004). By contrast, although VEGF-A splice isoforms were described for the first time in 1989, very little is known about the molecular mechanisms that control $V E G F-A$ pre-mRNA splicing (Fig. 6.3).

\subsubsection{Molecular Determinants of $V E G F_{x x x}$ Pre-mRNA Splicing}

It was previously shown that the splicing factor SAM68 (Cohen et al. 2005), the U2AF65related protein CAPER (Dowhan et al. 2005), and a putative chloride channel, pICn (Li et al. 2004), control $V E G F_{x x x}$ pre mRNA splicing. Progesterone selectively was reported to increase the expression of the $\mathrm{VEGF}_{189}$ isoform in the human uterus (Ancelin et al. 2002). Moreover, an exonic splicing silencing (ESS) sequence was recently described in exon 6a, though the regulatory proteins interacting with it remain unknown (Wang et al. 2009). In endometrial cancer cells, low $\mathrm{pH}$ (acidosis) significantly upregulated the $V E G F_{121}$ mRNA level when compared with the 145,165 , or 189 isoforms through a mechanism involving the p38 MAPK pathway and splicing factors of the SR proteins family, namely SRSF1 (formerly SF2/ASF), SRp20, and SRp40 (Elias and Dias 2008). In addition, incubation with phorbol myristate acetate (PMA), an activator of PKC activity, induced the expression of $\mathrm{VEGF}_{206}$ in human skin mast cells, which normally express the 121, 165, and 189 isoforms (Grutzkau et al. 1998). As previously discussed, $V E G F_{111}$ mRNA was specifically induced by genotoxic stress in several tumor cell lines and human xenografts in nude mice upon treatment with camptothecin (Mineur et al. 2007); however, the molecular mechanisms involved remain unknown.

\subsubsection{Molecular Pathways that Control the Balance Between $V_{E G F} F_{x x}$ and $V_{E G F} b$ Splice Variants}

Bates's group has mainly contributed to the identification of upstream regulators of the VEGF $_{\mathrm{xxx}} \mathrm{b}$ isoforms. In 2008, Nowak and colleagues first demonstrated in primary epithelial cells that insulin growth factor (IGF1) and tumor necrosis factor alpha (TNF- $\alpha$ ) treatment favor the selection of the PSS, thereby increasing $\mathrm{VEGF}_{\mathrm{xxx}}$ production, whereas tumor growth factor beta 1 (TGF- $\beta 1$ ) favors DSS selection, increasing VEGF $\mathrm{xxx}_{\mathrm{x}} \mathrm{b}$ (Nowak et al. 2008) (Fig. 6.3). Using epithelial cells overexpressing various SR proteins, these authors further demonstrated that SRSF1 favors PSS selection by binding a 35-nucleotide sequence of exon 
8a upstream of PSS, whereas SRSF6 (formerly SRp55) favors DSS by binding to a 35nucleotide region of the 3'UTR immediately downstream of the stop codon in exon $8 \mathrm{~b}$. TGF$\beta 1$ action requires the activity of p38 MAPK and CLK/STY kinases, whereas IGF1 involves both PKC and SRPK1/2, the latter being the specific kinases of SR proteins (Nowak et al. 2010). Consistent with a crucial role of SR proteins in controlling the balance between $\mathrm{VEGF}_{\mathrm{xxx}}$ and $\mathrm{VEGF}_{\mathrm{xxx}} \mathrm{b}$ isoforms both under normal and pathological conditions, elevated VEGF $_{165}$ b expression was correlated with the increased expression of TGF- $\beta 1$ and SRSF6 in keratinocytes, fibroblasts, endothelial cells, and perivascular inflammatory cells of patients suffering from systemic sclerosis (Manetti et al. 2011). In addition, we provided the first evidence that the transcription factor E2F1 favors $V_{E G F}$ b5 expression via a mechanism involving SRSF2 (formerly SC35), another SR protein, in lung adenocarcinoma cell lines and xenografts in nude mice (Merdzhanova et al. 2010). Later, Bates and colleagues showed that mutations in WT1, the Wilms' tumor suppressor gene, suppress $\mathrm{VEGF}_{165} \mathrm{~b}$ expression and cause abnormal gonadogenesis, renal failure, and Wilms' tumors (Amin et al. 2011). In WT1 mutants, SRPK1 was upregulated through the derepression of its transcription, leading to the phosphorylation and nuclear accumulation of SRSF1, thereby favoring $\mathrm{VEGF}_{\mathrm{xxx}}$ isoforms. Interestingly, sodium butyrate $(\mathrm{NaBu})$, a histone deacetylase inhibitor, increased $V E G F_{121} b$, $V E G F_{165} b$, and $V E G F_{189} b$ mRNA and protein levels in immortalized human lung microvascular endothelial cells (HLMECs) (Ciura and Jagodzinski 2010). As we demonstrated that the treatment of human lung adenocarcinoma cell lines with $\mathrm{NaBu}$ or cisplatin increased the expression level of SRSF2 (Edmond et al. 2011a; Edmond et al. $2011 \mathrm{~b}$ ), it is tempting to speculate that therapies could modify $V E G F-A$ pre-mRNA splicing through the modulation of SR protein expression (see 6.2.2). In addition, as pre-mRNA splicing is known to occur co-transcriptionally, one might postulate that SR proteins could cooperate with the transcription factors that control $V E G F-A$ transcription to modulate $V E G F$ $A$ pre-mRNA splicing, as we found for E2F1 and SRSF2. Whether HIF1 plays a role in this scenario remains a very intriguing question.

\subsection{Does $V E G F-A$ Pre-mRNA Splicing Play a Role in the Response to Anti-Angiogenic Therapies?}

\subsubsection{Anti-Angiogenic Therapy Failure: Patient Selection Is Critical}

One of the main problems with the use of anti-angiogenic therapies is the absence of effective predictive biomarkers. In a meta-analysis of published randomized controlled trials (RCTs), Ranpura and colleagues showed that the addition of bevacizumab is associated with an increased risk of fatal adverse events (FAEs) in patients receiving taxanes or platinum salts compared with chemotherapy alone (Ranpura et al. 2011) and was not restricted to an antiVEGF antibody. Indeed, another meta-analysis derived from 10 randomized RCTs and including 4679 patients receiving either sorafenib, sunitinib, or pazopanib also found an increased risk of FAEs following the use of these VEGFR TKIs compared with control patients (Schutz et al. 2012). Therefore, biomarkers are urgently needed to select patients that will benefit from such therapies. In addition, a better understanding of the molecular mechanisms involved in primary or acquired tumor resistance to these therapies is crucial in the development of new therapeutic strategies. 


\subsubsection{Anti-Angiogenic Therapies Used Alone or in Combination Regulate VEGF-A Pre-mRNA Splicing}

Several clinical studies have shown acute increases or decreases in circulating total VEGF-A levels after bevacizumab delivery (Lambrechts et al. 2013). By contrast, the impact of antiangiogenic therapies on $V E G F-A$ pre-mRNA splicing has not yet been investigated. We recently addressed this question and provided the first evidence that treating human lung adenocarcinoma cell lines with bevacizumab alters the VEGF $_{165}$ b:pan-VEGF ratio in favor of VEGF $_{165}$ b (Boudria et al in preparation). Similar results were obtained when SU5416, a VEGFR TKI, was used. Consistent with our data, intravitreal bevacizumab injection in an oxygen-induced retinopathy mouse model also increased the relative protein expression of the VEGF $_{165} \mathrm{~b}$ isoform while inhibiting the protein level of total VEGF-A isoforms (Shi et al. 2013). Although these results must be extended to other tumor types and/or other VEGFR TKIs, such as sorafenib or sunitinib, they demonstrate the impact of anti-angiogenic therapies on $V E G F-A$ pre-mRNA splicing.

Bevacizumab is never used alone and is always combined with conventional chemotherapies for the treatment of breast, lung, colon, and kidney carcinomas. However, as it has been shown that chemotherapies increase $V E G F-A$ mRNA expression in cancer cells (Fan, Gray et al. 2008), it is possible that chemotherapies either used alone or in combination with antiangiogenic therapies also impact $V E G F-A$ pre-mRNA splicing. In NSCLCs, bevacizumab is combined with platinum salts (cisplatin or carboplatin) and with paclitaxel or gemcitabin. Interestingly, we found that treating NSCLC cell lines with these drugs significantly increased the $\mathrm{VEGF}_{165} \mathrm{~b}$ protein level, though decreased the expression of total VEGF-A (Boudria et al in preparation). More interestingly, when bevacizumab was added to these chemotherapies, a stronger accumulation of $V_{E G F}{ }_{165} b$ protein was observed in these cells, and $V_{E G F}{ }_{165} b$ prevented cisplatin-induced apoptosis. Therefore, the combination of bevacizumab and cisplatin could select tumor cells that are more resistant to apoptosis through the upregulation of $\mathrm{VEGF}_{165} \mathrm{~b}$. Of note, cells overexpressing $\mathrm{VEGF}_{165} \mathrm{~b}$ were also less sensitive to hypoxiainduced apoptosis, thereby suggesting that $V_{E G F}{ }_{165} \mathrm{~b}$ could be a general inhibitor of apoptosis. Our results are consistent with recent data demonstrating that $\mathrm{VEGF}_{165} \mathrm{~b}$ exerts a neuroprotective function in hippocampal, cortical, and retinal neurons by activating VEGFR2 and p42/44 MAPK and preventing apoptosis (Beazley-Long et al. 2013).

Therefore, such anti-angiogenic therapies as bevacizumab, alone or in combination with chemotherapies, appear able to control $V E G F-A$ pre-mRNA splicing and to favor the expression of $\mathrm{VEGF}_{\mathrm{xxx}} \mathrm{b}$ isoforms, at least in NSCLC cell lines. Such an effect might play a role in tumor adaptative resistance (see 6.2.3 and 6.2.4). Whether SR proteins are involved in this alternative switch remains largely unknown, but we observed that cisplatin, bevacizumab, and SU5416 increased SRSF2 and SRSF6 protein levels in our cellular models, a result that was consistent with $\mathrm{VEGF}_{\mathrm{xxx}} \mathrm{b}$ accumulation. In addition, whether chemotherapies and/or anti-angiogenic therapies control the expression level of distinct $\mathrm{VEGF}_{\mathrm{xxx}} / \mathrm{VEGF}_{\mathrm{xxx}} \mathrm{b}$ splice variants from each VEGF-A sub-family remains to be determined. 


\subsubsection{VEGF-A Splice Variants: Can They Predict Responses to Anti- Angiogenic Treatments?}

\subsubsection{The VEGF vxx $_{\mathrm{x}} \mathrm{b} / \mathrm{pan}-\mathrm{VEGF}$ Ratio: A Predictive Biomarker of Responses to Bevacizumab}

The discovery of the $\mathrm{VEGF}_{\mathrm{xxx}} \mathrm{b}$ sub-family has complicated the simple view that targeting VEGF-A could be beneficial to patients. Hence, VEGF-A was found to encode both "bad" (pro) and "good" (anti)-angiogenic isoforms, which are both targeted by bevacizumab with the same affinity, leading to the question of whether $V E G F-A$ pre-mRNA splicing is the key to anti-angiogenic therapeutics (Harper and Bates 2008). The first evidence demonstrating that $\mathrm{VEGF}_{165} \mathrm{~b}$ expression has an impact on the efficacy of bevacizumab came from the study of Varey and colleagues (Varey et al. 2008), who showed that xenografts in mice derived from human $\mathrm{VEGF}_{165}$ b-overexpressing colon cancer cells grow more slowly than those bearing $\mathrm{VEGF}_{165}$-overexpressing cancer cells. Consistent with an impairment of tumor angiogenesis, the VEGF $_{165}$ b-overexpressing xenografts were less vascularized and displayed greater areas of necrosis. More importantly, the authors further demonstrated that the dose of bevacizumab required to prevent tumor growth in $\mathrm{VEGF}_{165}$-overexpressing tumors had no effect on the $\mathrm{VEGF}_{165} \mathrm{~b}$-expressing tumors. This in vitro model predicting that bevacizumab would be less efficient in colorectal cancer patients who exhibited an excess of $\mathrm{VEGF}_{\mathrm{xxx}} \mathrm{b}$ over VEGF $\mathrm{xxx}_{\mathrm{xx}}$ compared with those with an excess of $\mathrm{VEGF}_{\mathrm{xxx}}$ was recently validated in situ. In 149 metastatic colorectal cancer patients from the E3200 clinical trial of FOLFOX4 \pm bevacizumab, the unadjusted analysis of the progression-free survival (PFS) showed a significantly better outcome for patients with intra-tumoral $\mathrm{VEGF}_{165} \mathrm{~b}_{\mathrm{V}} \mathrm{VEGF}_{\text {total }}$ ratio scores below the median treated with FOLFOX4+BVZ compared with FOLFOX4 alone (Bates et al. 2012). Although these data need to be extend to a larger series of patients and to other tumor types, they suggest that a low $\mathrm{VEGF}_{165} \mathrm{~b}: \mathrm{VEGF}_{\text {total }}$ ratio might be a predictive marker for response to bevacizumab, at least in metastatic colorectal cancer. In addition, studies investigating the predictive potential of $\mathrm{VEGF}_{\mathrm{xxx}} \mathrm{b}$ in response to other anti-angiogenic therapies used clinically, such as VEGFR TKIs, are lacking. As the VEGF $\mathrm{xxx}_{\mathrm{x}} \mathrm{b}$ isoforms antagonize VEGFR1/VEGFR2 angiogenic signaling, one might predict that patients with significant levels of $\mathrm{VEGF}_{\mathrm{xxx}} \mathrm{b}$ would be less sensitive to VEGFR TKIs.

Importantly, a lack of correlation between intra-tumoral and plasma VEGF-A protein levels was recently demonstrated (Hegde et al. 2013); however, it is not known to date whether this is also true for $\mathrm{VEGF}_{\mathrm{xxx}} \mathrm{b}$ isoforms. Therefore, both the circulating and tumoral $\mathrm{VEGF}_{\text {total }}$ and $\mathrm{VEGF}_{\mathrm{xxx}} \mathrm{b}$ levels should be taken into account when seeking a correlation between VEGF-A status and tumor response to anti-angiogenic treatments in situ.

\subsubsection{Plasma Level of Short VEGF-A Isoforms but Not of Total VEGF-A Predict Outcome after Anti-Angiogenic Therapies}

In NSCLC and colorectal and renal cell carcinomas, an association between a high circulating VEGF-A level and a shortened progression-free or overall survival was recently described, regardless of bevacizumab treatment (Hegde et al. 2013). Therefore, the plasma levels of total VEGF-A can serve as a prognostic rather than a predictive marker. However, when an ELISA assay that preferentially detects short VEGF-A isoforms $\left(\mathrm{VEGF}_{121}\right.$ and VEGF 111$)$ was used, an association between high basal plasma levels of VEGF $_{121}$ and improved PFS and/or overall survival (OS) after bevacizumab treatment was found in breast, pancreatic, and gastric 
carcinomas but not in metastatic colorectal, renal, and lung cancers (Lambrechts et al. 2013). Therefore, $\mathrm{VEGF}_{121}$ appears to be a promising candidate biomarker for bevacizumab response, at least in certain cancers. As previously discussed, the discrepancy between tumors might reflect a distinct role of the $\mathrm{VEGF}_{\mathrm{xxx}}$ isoforms depending on the tumor type and/or chemotherapies combined with anti-angiogenic treatments. In addition, the used of citrated plasma, which has minimal effect on platelet activation, rather than EDTA-treated plasma could also affect the results.

\subsubsection{VEGF-A Splice Variants as Predictive Biomarkers for Anti-Angiogenic Therapies: How Does It Work?}

\subsubsection{Paracrine Effects on Endothelial Cells}

Several hypotheses have been proffered regarding $\operatorname{VEGF}_{165} \mathrm{~b}$ potential as a predictive biomarker for bevacizumab response. First, it has been proposed that the concentration of effective bevacizumab could be lowered in patients with higher $V_{E G F}{ }_{165} \mathrm{~b}$ concentrations, as more of the antibody is bound to VEGF ${ }_{165} \mathrm{~b}$ and not to $\mathrm{VEGF}_{165}$, thereby diminishing the antiangiogenic activity of $V_{E G F}{ }_{165} \mathrm{~b}$ while increasing the amount of free pro-angiogenic $\mathrm{VEGF}_{165}$. Conversely, patients with lower $\mathrm{VEGF}_{165} \mathrm{~b}$ levels may have a more angiogenicprogressive tumor than the high $\mathrm{VEGF}_{165} \mathrm{~b}$ group, thereby rendering the tumor more susceptible to bevacizumab+FOLFOX (Bates et al. 2012). This more angiogenic profile could also explain why patients with higher levels of soluble VEGF $_{121}$ are more susceptible to bevacizumab, as this diffusible short isoform may more accurately reflect the levels of bioactive VEGF-A and the vascular dependence of the tumor. This hypothesis is also consistent with another study identifying a VEGF-dependent gene signature specifically expressed in the tumor vascular compartment in which high expression correlated with enhanced VEGF-A downstream bioactivity and with an increased response to bevacizumab in colorectal cancers (Brauer et al. 2013). Alternatively, as bevacizumab does not prevent interaction between VEGF-A and NRP1 or NRP2, blocking the VEGF-A/VEGFR signaling pathways could induce compensatory mechanisms leading to the activation of VEGF/NRPdependent networks. Consistently, it has been shown that anti-NRP1 antibodies have an additive effect on anti-VEGF therapy in reducing tumor growth through vessel normalization (Pan et al. 2007b). As the $\mathrm{VEGF}_{\mathrm{xxx}}$ and $\mathrm{VEGF}_{\mathrm{xxx}} \mathrm{b}$ isoforms do not display the same affinity for NRP, such a compensatory response to anti-angiogenic therapies could thereby be dependent on the balance between both VEGF-A sub-families.

\subsubsection{Autocrine Effects on Tumor Cells}

Compared with the large number of publications related to VEGF-A endothelial functions, only a few studies have analyzed its autocrine effects on tumor cells that express VEGFR and/or NRP. Moreover, almost nothing is known regarding the functions of distinct VEGF-A splice variants in this setting. This situation is somewhat surprising because anti-angiogenic therapies, first designed to target endothelial cells, might directly impact the tumors themselves via the regulation of this autocrine loop. Alternatively, VEGF-A-regulated autocrine loops could contribute to primary or acquired resistance to these therapies. 
VEGF-A: Not Only a Pro-Tumoral Factor in Tumor Cells?

It is currently acknowledged that VEGF-A exerts pro-proliferative/survival functions on tumor cells (Lichtenberger et al. 2010). As an example, the VEGF-A/VEGFR2/NRP1 autocrine loop was found to promote glioma stem-like cell viability and tumor growth and to limit the impact of bevacizumab treatment (Hamerlik et al. 2012). However, recent studies have highlighted unexpected VEGF-A anti-tumoral functions, increasing the complexity of the approach that blocking VEGF-A would always be beneficial. Indeed, $\mathrm{VEGF}_{189}$ was found to induce NRP1-dependent apoptosis in breast cancer cell lines, whereas $\mathrm{VEGF}_{165}$ acted as a survival factor (Vintonenko et al. 2011). In addition, the combination of high VEGF-A, VEGFR1, and VEGFR2 protein expression was associated with an improved progression-free survival in early squamous cell carcinoma of the lung in those who are not eligible for bevacizumab treatment owing to severe complications (Pajares et al. 2012). It is noteworthy that this effect was independent of endothelial cells, as no correlation was found between VEGF or its receptors and microvessel density. More strikingly, VEGF $_{165}$ was highlighted as a negative regulator of tumor cell invasion in glioblastoma through the inhibition of c-Met activity ( $\mathrm{Lu}$ et al. 2012). In resistant glioblastoma patients, bevacizumab increased MET activation and contributed to the emergence of cells with a more invasive phenotype, which correlated with the expression of mesenchymal markers (Lu et al. 2012; Jahangiri et al. 2013). Taken together, these data highlight the distinct autocrine functions of $\mathrm{VEGF}_{\mathrm{xxx}}$ splice variants in tumors and their potential as determinants of tumor responses to anti-angiogenic therapies.

\section{VEGF ${ }_{165} b:$ A Pro-Invasive Factor in NSCLCs}

In human lung adenocarcinoma cell lines and mouse xenografts, we found that bevacizumab treatment triggered a more invasive phenotype that correlated with the activation of both the VEGFR1 and VEGFR2 signaling pathways and with the acquisition of some mesenchymal markers and the secretion of metalloproteases (Boudria et al in preparation). Importantly, because the specific neutralization of $\mathrm{VEGF}_{165} \mathrm{~b}$ by siRNA was found to reverse the effects mediated by bevacizumab and to inhibit tumor growth, all these effects were dependent on $\mathrm{VEGF}_{165} \mathrm{~b}$, but not $\mathrm{VEGF}_{165}$, expression. Conversely and consistent with $\mathrm{VEGF}_{165} \mathrm{~b}$ controlling a pro-tumoral autocrine loop in NSCLCs, xenografts derived from $\mathrm{VEGF}_{165} \mathrm{~b}$ overexpressing cells, despite being less angiogenic, grew more rapidly than control tumors and displayed markers of EMT. Altogether, our data support a model in which bevacizumab induces a more invasive phenotype through the activation of a $\mathrm{VEGF}_{165}$ b-dependent autocrine loop (Boudria et al in preparation). Our results are somewhat consistent with the results of Catena and colleagues who showed that the stable overexpression of either $\mathrm{VEGF}_{121} \mathrm{~b}$ or $\mathrm{VEGF}_{165}$ b protein in A549 human lung adenocarcinoma cells resulted in a significant increase in tumor development over the controls, even though no significant differences in vascular density were found. Additionally, in prostate PC-3 xenografted tumors, a reduction, as opposed to an increase, in the number of apoptotic cells was observed when $\mathrm{VEGF}_{\mathrm{xxx}} \mathrm{b}$ overexpressing cells were injected, as compared with controls (Catena et al. 2010). Although we were not able to examine the correlation between $\mathrm{VEGF}_{165} \mathrm{~b}$ status and response to bevacizumab in situ in NSCLC patients, our findings correlate well with our observations associating high $\mathrm{VEGF}_{165} \mathrm{~b}$ protein levels with lymph node metastases in NSCLC. The data also suggested that NSCLC patients with high $\mathrm{VEGF}_{165} \mathrm{~b}$ levels could be less sensitive to bevacizumab, whereas bevacizumab could contribute to the emergence of more invasive tumor cells in patients displaying lower $\mathrm{VEGF}_{165} \mathrm{~b}$ levels. Therefore, the balance between $\mathrm{VEGF}_{\mathrm{xxx}}$ and $\mathrm{VEGF}_{\mathrm{xxx}} \mathrm{b}$ isoforms also controls the autocrine loops potentially involved in tumor responses to anti-angiogenic therapies. 
Taken together, all these studies provide evidence that both VEGF-A-dependent paracrine and autocrine loops must be taken into account when investigating the overall response to antiangiogenic therapies. In addition, until more details are known regarding the role and expression of distinct VEGF-A splice variants, it should be considered that the impact of antiangiogenic therapies could be drastically different, even deleterious, depending on the tumor type and/or which VEGF-A splice variant is expressed.

\subsubsection{Pre-mRNA Splicing: A Reservoir of Biomarkers for Anti-Angiogenic Treatments}

In addition to VEGF-A, many proteins involved in the angiogenic cascade are alternatively spliced isoforms. As an example, the pre-mRNA alternative splicing of VEGFR1, VEGFR2, or NRP1 generates soluble splice receptors that can, or are predicted to, act as natural inhibitors. Consistent with a role of these splice variants in responses to anti-angiogenic treatments, posttreatment changes in plasma sVEGFR2 were significantly correlated with tumor shrinkage in NSCLC patients treated with pazopanib (Nikolinakos et al. 2010). In addition, sVEGFR1 plasma levels were inversely correlated with the outcome of patients treated with either bevacizumab or anti-VEGFR TKIs in rectal, metastatic colorectal, and breast cancers and hepatocellular carcinoma (Lambrechts et al. 2013). Conversely, low intratumoral VEGFR1 expression was found to correlate with improved progression-free or overall survival after bevacizumab delivery in colorectal and gastric carcinomas, respectively. Therefore, it appears that a switch in VEGFR1 pre-mRNA splicing occurs in tumors and could play a role in the response to anti-angiogenic therapies. Such an effect could be related to a recent study demonstrating that VEGF-A itself induces the expression of sVEGFR1 while leaving expression of the full-length VEGFR1 unchanged in human vascular endothelial cells via a mechanism involving the VEGFR2 protein kinase cMEK signaling pathway (Saito et al. 2013). Although further analyses dissecting the role played by these splice variants during the response to anti-angiogenic therapies are needed, it is likely that pre-mRNA splicing will highlight new potential biomarkers in the future (Fig. 6.4).

\subsubsection{Combining Anti-Angiogenic Therapies with Drugs Targeting the Pre- mRNA Splicing Machinery: New Therapeutic Strategies in the Future}

Based on the above data, one might propose that novel therapeutic strategies combining both anti-angiogenic therapies with drugs targeting the pre-mRNA splicing machinery should be developed (Fig 6.4). SRPK inhibitors are among these new drug candidates, as their use is thought to reduce the synthesis of pro-angiogenic isoforms of VEGF-A, consequently decreasing angiogenesis. Consistent with such a hypothesis, selective SRPK inhibitors reduce choroidal neovascularization in vivo when administered topically (eye drop) in rats and mice with exudative age-related macular degeneration (wet AMD) (Gammons et al. 2013). In addition, the injection of SRPIN340, an SRPK1/2 inhibitor, reduced angiogenesis in a mouse model of retinal neovascularization (Nowak et al. 2010). SRPKs could also be a good target in cancer as they are overexpressed in many tumor types compared with normal tissues, including NSCLC (Gout et al. 2012). Indeed, SRPK1 inhibition prevented angiogenesis and associated tumor growth in Wilm's tumors (Amin et al. 2011). Although decreasing the expression of pro-angiogenic $\mathrm{VEGF}_{\mathrm{xxx}}$ isoforms while increasing that of anti-angiogenic 
VEGF $_{\mathrm{xxx}} \mathrm{b}$ might not always be beneficial (see 6.2.4), SRPK inhibitors could cooperate with anti-angiogenic therapies to prevent neovascularization and tumor growth in certain tumor types. More generally, pharmacological inhibitors of other components of the spliceosome are currently tested in cancer, one of which, spliceostatin A, was found to block angiogenesis by reducing the total amount of VEGF transcript (Furumai et al. 2010). Therefore, additional experiments are needed to select the most appropriate drug and combination. In addition, further experiments are needed to improve our fundamental knowledge regarding the contribution of pre-mRNA splicing to angiogenesis and response to anti-angiogenic therapies. To this end, the development of new tools/assays that recognize specific VEGF-A splice variants is crucial to clarify what, if any, role distinct VEGF-A splice isoforms have during the tumorigenic process and the response to anti-angiogenic therapies.

\section{Figure captions}

Fig. 6.1 a The human $V E G F-A$ gene structure, consisting of eight exons and seven introns. b Focus on the C-terminal exon 8 of $V E G F-A$, the splicing of which generates either the VEGF $_{\mathrm{xxx}}$ or $\mathrm{VEGF}_{\mathrm{xxx}} \mathrm{b}$ sub-family. The proximal splice site (PSS) and distal splice site (DSS) are indicated. The nucleotide and amino acid sequences for exons $8 \mathrm{a}$ and $8 \mathrm{~b}$ are depicted. c Illustration of all VEGF-A splice variants in each sub-family. The extracellular matrix affinity of the corresponding VEGF-A isoforms is indicated.

Fig. 6.2 Scheme of the functional domains of the VEGF-A protein encoded by each exon. The basic residues that confer affinity to heparin-containing proteoglycans are indicated. Because VEGF $_{165} \mathrm{~b}$ does not bind heparin, it has been proposed that exon $8 \mathrm{~b}$ could exert a negative effect on heparin binding. Alternatively, exon 8a is required for heparin binding. Exons 3 and 4 encode VEGFR1 and VEGFR2 binding domains. Exons 5, 7, and 8a encode sequences that are required for VEGF-A binding to neuropilins. As a consequence, $\mathrm{VEGF}_{\mathrm{xxx}} \mathrm{b}$ isoforms do not bind neuropilins.

Fig. 6.3 a The upstream stimuli that have been shown to modify the balance between $\mathrm{VEGF}_{\mathrm{xxx}}$ and $\mathrm{VEGF}_{\mathrm{xxx}} \mathrm{b}$ isoforms. b The cellular signaling pathways that affect the choice between the proximal splice site (PSS) and distal splice site (DSS) in exon 8, thereby allowing the expression of either the $\mathrm{VEGF}_{\mathrm{xxx}}$ or $\mathrm{VEGF}_{\mathrm{xxx}} \mathrm{b}$ splice variant. The SRSF1 protein favors PSS selection, whereas the SRSF6 or SRSF2 protein favors DSS. The potential link between RNA and DNA machineries are illustrated. In this setting, transcription factors, such as E2F1, could cooperate with SR proteins to control pre-mRNA splicing. In addition, the elongation rate of DNA polymerase II could also affect pre-mRNA splicing. TF: transcription factor.

Fig. 6.4 Relationships between pre-mRNA splicing and the response to anti-angiogenic therapies. Pre-mRNA splicing is proposed as a reservoir for predictive biomarkers. New therapeutic strategies combining both anti-angiogenic therapies and drugs targeting the premRNA splicing machineries are illustrated as such a combination that could modulate the expression level of these pre-mRNA splice variants and thereby improve patient outcomes. 


\section{References}

Amin EM, Oltean S, Hua J et al (2011) WT1 mutants reveal SRPK1 to be a downstream angiogenesis target by altering VEGF splicing. Cancer Cell 20: 768-780

Ancelin M, Buteau-Lozano H, Meduri G et al (2002) A dynamic shift of VEGF isoforms with a transient and selective progesterone-induced expression of VEGF189 regulates angiogenesis and vascular permeability in human uterus. Proc Natl Acad Sci U S A 99: 6023-6028

Ballmer-Hofer K, Andersson AE, Ratcliffe LE et al (2011) Neuropilin-1 promotes VEGFR-2 trafficking through Rab11 vesicles thereby specifying signal output. Blood 118: 816-826

Bates DO, Catalano PJ, Symonds KE et al (2012) Association between VEGF splice isoforms and progressionfree survival in metastatic colorectal cancer patients treated with bevacizumab. Clin Cancer Res 18: 6384-6391

Bates DO, Cui TG, Doughty JM et al (2002) VEGF165b, an inhibitory splice variant of vascular endothelial growth factor, is down-regulated in renal cell carcinoma. Cancer Res 62: 4123-4131

Bates DO, MacMillan PP, Manjaly JG et al (2006) The endogenous anti-angiogenic family of splice variants of VEGF, VEGFxxxb, are down-regulated in pre-eclamptic placentae at term. Clin Sci (Lond) 110: 575585

Beazley-Long N, Hua J, Jehle T et al (2013) VEGF-A165b Is an Endogenous Neuroprotective Splice Isoform of Vascular Endothelial Growth Factor A in Vivo and in Vitro. Am J Pathol 183: 918-929

Brauer MJ, Zhuang G, Schmidt M et al (2013) Identification and analysis of in vivo VEGF downstream markers link VEGF pathway activity with efficacy of anti-VEGF therapies. Clin Cancer Res 19: 3681-3692

Catena R, Larzabal L, Larrayoz M et al (2010) VEGF(1)(2)(1)b and VEGF(1)(6)(5)b are weakly angiogenic isoforms of VEGF-A. Mol Cancer 9: 320-327

Catena R, Muniz-Medina V, Moralejo B et al (2007) Increased expression of VEGF121/VEGF165-189 ratio results in a significant enhancement of human prostate tumor angiogenesis. Int J Cancer 120: 20962109

Cebe Suarez S, Pieren M, Cariolato L et al (2006) A VEGF-A splice variant defective for heparan sulfate and neuropilin-1 binding shows attenuated signaling through VEGFR-2. Cell Mol Life Sci 63: 2067-2077

Chen TT, Luque A, Lee S et al (2010) Anchorage of VEGF to the extracellular matrix conveys differential signaling responses to endothelial cells. J Cell Biol 188: 595-609

Cheung CY, Singh M, Ebaugh MJ et al (1995) Vascular endothelial growth factor gene expression in ovine placenta and fetal membranes. Am J Obstet Gynecol 173: 753-759

Ciura J, Jagodzinski PP (2010) Butyrate increases the formation of anti-angiogenic vascular endothelial growth factor variants in human lung microvascular endothelial cells. Mol Biol Rep 37: 3729-3734

Cohen CD, Doran PP, Blattner SM et al (2005) Sam68-like mammalian protein 2, identified by digital differential display as expressed by podocytes, is induced in proteinuria and involved in splice site selection of vascular endothelial growth factor. J Am Soc Nephrol 16: 1958-1965

Cui TG, Foster RR, Saleem M et al. (2004) Differentiated human podocytes endogenously express an inhibitory isoform of vascular endothelial growth factor (VEGF165b) mRNA and protein. Am J Physiol Renal Physiol 286: 767-773

David CJ, Manley JL (2010) Alternative pre-mRNA splicing regulation in cancer: pathways and programs unhinged. Genes Dev 24: 2343-2364

Delcombel R, Janssen L, Vassy R et al (2013) New prospects in the roles of the C-terminal domains of VEGF-A and their cooperation for ligand binding, cellular signaling and vessels formation. Angiogenesis 16 : 353-371

Diaz R, Pena C, Silva J et al (2008) p73 Isoforms affect VEGF, VEGF165b and PEDF expression in human colorectal tumors: VEGF165b downregulation as a marker of poor prognosis. Int J Cancer 123: 10601067

Dowhan DH, Hong EP, Auboeuf D et al (2005) Steroid hormone receptor coactivation and alternative RNA splicing by U2AF65-related proteins CAPERalpha and CAPERbeta. Mol Cell 17: 429-439

Edmond V, Brambilla C, Brambilla E et al (2011a) SRSF2 is required for sodium butyrate-mediated p21(WAF1) induction and premature senescence in human lung carcinoma cell lines. Cell Cycle 10: 1968-1977

Edmond V, Moysan E, Khochbin S et al (2011b) Acetylation and phosphorylation of SRSF2 control cell fate decision in response to cisplatin. EMBO J 30: 510-523

Elias AP, Dias S (2008) Microenvironment changes (in $\mathrm{pH}$ ) affect VEGF alternative splicing. Cancer Microenviron 1: 131-139 
Fan F, Gray MJ, Dallas NA et al (2008) Effect of chemotherapeutic stress on induction of vascular endothelial growth factor family members and receptors in human colorectal cancer cells. Mol Cancer Ther 7: 3064-3070

Faure, C, Linossier MT, Malaval L et al (2008) Mechanical signals modulated vascular endothelial growth factor-A (VEGF-A) alternative splicing in osteoblastic cells through actin polymerisation. Bone 42: 1092-1101

Ferrara N (2004) Vascular endothelial growth factor: basic science and clinical progress. Endocr Rev 25: 581611

Furumai R, Uchida K, Komi Y et al (2010) Spliceostatin A blocks angiogenesis by inhibiting global gene expression including VEGF. Cancer Sci 101: 2483-2489

Gammons MV, Federov O, Ivison D et al (2013) Topical anti-angiogenic SRPK1 inhibitors reduce choroidal neovascularization in rodent models of exudative-AMD. Invest Ophthalmol Vis Sci. 54: 6052-6062

Gout S, Brambilla E, Boudria A et al (2012) Abnormal expression of the pre-mRNA splicing regulators SRSF1, SRSF2, SRPK1 and SRPK2 in non small cell lung carcinoma. PLoS One 7: e46539

Grepin R, Guyot M, Jacquin M et al (2012) Acceleration of clear cell renal cell carcinoma growth in mice following bevacizumab/Avastin treatment: the role of CXCL cytokines. Oncogene 31: 1683-1694

Grunstein J, Masbad JJ, Hickey R et al (2000) Isoforms of vascular endothelial growth factor act in a coordinate fashion To recruit and expand tumor vasculature. Mol Cell Biol 20: 7282-7291

Grutzkau A, Kruger-Krasagakes S, Baumeister H et al. (1998) Synthesis, storage, and release of vascular endothelial growth factor/vascular permeability factor (VEGF/VPF) by human mast cells: implications for the biological significance of VEGF206. Mol Biol Cell 9: 875-884

Hamerlik P, Lathia JD, Rasmussen R et al (2012) Autocrine VEGF-VEGFR2-Neuropilin-1 signaling promotes glioma stem-like cell viability and tumor growth. J Exp Med 209: 507-520

Harper SJ, Bates DO (2008) VEGF-A splicing: the key to anti-angiogenic therapeutics? Nat Rev Cancer 8: 880887

Hegde PS, Jubb AM, Chen D et al (2013) Predictive impact of circulating vascular endothelial growth factor in four phase III trials evaluating bevacizumab. Clin Cancer Res 19: 929-937

Houck KA, Ferrara N, Winer J et al (1991) The vascular endothelial growth factor family: identification of a fourth molecular species and characterization of alternative splicing of RNA. Mol Endocrinol 5: 1806 1814

Houck KA, Leung DW, Rowland AM et al (1992) Dual regulation of vascular endothelial growth factor bioavailability by genetic and proteolytic mechanisms. J Biol Chem 267: 26031-26037

Jahangiri A, De Lay M, Miller LM et al (2013) Gene expression profile identifies tyrosine kinase c-Met as a targetable mediator of antiangiogenic therapy resistance. Clin Cancer Res 19: 1773-1783

Jingjing L, Xue Y, Agarwal N et al (1999) Human Muller cells express VEGF183, a novel spliced variant of vascular endothelial growth factor. Invest Ophthalmol Vis Sci 40: 752-759

Kawai H, Minamiya Y, Ito M et al (2008) VEGF121 promotes lymphangiogenesis in the sentinel lymph nodes of non-small cell lung carcinoma patients. Lung Cancer 59: 41-47

Kawamura H. Li X, Harper SJ et al (2008) Vascular endothelial growth factor (VEGF)-A165b is a weak in vitro agonist for VEGF receptor-2 due to lack of coreceptor binding and deficient regulation of kinase activity. Cancer Res 68: 4683-4692

Keyt BA, Berleau LT, Nguyen HV et al (1996) The carboxyl-terminal domain (111-165) of vascular endothelial growth factor is critical for its mitogenic potency. J Biol Chem 271: 7788-7795

Ladomery MR, Harper SJ, Bates DO (2007) Alternative splicing in angiogenesis: the vascular endothelial growth factor paradigm. Cancer Lett 249: 133-142

Lambrechts D, Lenz HJ, de Haas S et al (2013) Markers of response for the antiangiogenic agent bevacizumab. J Clin Oncol 31: 1219-1230

Li H, Yonekura H, Kim CH et al (2004) Possible participation of pICln in the regulation of angiogenesis through alternative splicing of vascular endothelial growth factor receptor mRNAs. Endothelium 11: 293-300

Li N, Kanda K, Fukumori T et al (2000) Expression of vascular endothelial growth factor isoforms and plateletderived endothelial cell growth factor in bladder cancer. Urol Oncol 6: 10-15

Lichtenberger BM, Tan PK, Niederleithner H et al (2010) Autocrine VEGF signaling synergizes with EGFR in tumor cells to promote epithelial cancer development. Cell 140: 268-279

Ljungberg B, Jacobsen J, Haggstrom-Rudolfssson S et al (2003) Tumour vascular endothelial growth factor (VEGF) mRNA in relation to serum VEGF protein levels and tumour progression in human renal cell carcinoma. Urol Res 31: 335-340

Lu KV, Chang JP, Parachoniak CA et al (2012) VEGF inhibits tumor cell invasion and mesenchymal transition through a MET/VEGFR2 complex. Cancer Cell 22: 21-35 
Manetti M, Guiducci S, Romano E et al (2011) Overexpression of VEGF165b, an inhibitory splice variant of vascular endothelial growth factor, leads to insufficient angiogenesis in patients with systemic sclerosis. Circ Res 109: e14-26

Matsuyama M, Chijiwa T, Inoue Y et al (2009) Alternative splicing variant of vascular endothelial growth factor-A is a critical prognostic factor in non-small cell lung cancer. Oncol Rep 22: 1407-1413

Merdzhanova G, Gout S, Keramidas M et al (2010) The transcription factor E2F1 and the SR protein SC35 control the ratio of pro-angiogenic versus antiangiogenic isoforms of vascular endothelial growth factor-A to inhibit neovascularization in vivo. Oncogene 29: 5392-5403

Miller-Kasprzak E, Jagodzinski PP (2008) 5-Aza-2'-deoxycytidine increases the expression of anti-angiogenic vascular endothelial growth factor $189 \mathrm{~b}$ variant in human lung microvascular endothelial cells. Biomed Pharmacother 62: 158-163

Mineur P, Colige AC, Deroanne CF et al (2007) Newly identified biologically active and proteolysis-resistant VEGF-A isoform VEGF111 is induced by genotoxic agents. J Cell Biol 179: 1261-1273

Mourah S, Porcher R, Lescaille G et al (2009) Quantification of VEGF isoforms and VEGFR transcripts by qRT-PCR and their significance in acute myeloid leukemia. Int J Biol Markers 24: 22-31

Muller YA, Li B, Christinger HW et al (1997) Vascular endothelial growth factor: crystal structure and functional mapping of the kinase domain receptor binding site. Proc Natl Acad Sci U S A 94: 71927197

Nikolinakos PG, Altorki N, Yankelevitz D et al (2010) Plasma cytokine and angiogenic factor profiling identifies markers associated with tumor shrinkage in early-stage non-small cell lung cancer patients treated with pazopanib. Cancer Res 70: 2171-2179

Nowak DG, Amin EM, Rennel ES et al (2010) Regulation of vascular endothelial growth factor (VEGF) splicing from pro-angiogenic to anti-angiogenic isoforms: a novel therapeutic strategy for angiogenesis. J Biol Chem 285: 5532-5540

Nowak DG, Woolard J, Amin EM et al (2008) Expression of pro- and anti-angiogenic isoforms of VEGF is differentially regulated by splicing and growth factors. J Cell Sci 121: 3487-3495

Ohta Y, Endo Y, Tanaka M et al (1996) Significance of vascular endothelial growth factor messenger RNA expression in primary lung cancer. Clin Cancer Res 2: 1411-1416

Oshika Y, Nakamura M, Tokunaga T et al (1998) Expression of cell-associated isoform of vascular endothelial growth factor 189 and its prognostic relevance in non-small cell lung cancer. Int J Oncol 12: 541-544

Pajares MJ, Agorreta J, Larrayoz M et al (2012) Expression of tumor-derived vascular endothelial growth factor and its receptors is associated with outcome in early squamous cell carcinoma of the lung. J Clin Oncol 30: 1129-1136

Pan Q, Chanthery Y, Liang WC et al (2007b) Blocking neuropilin-1 function has an additive effect with antiVEGF to inhibit tumor growth. Cancer Cell 11:53-67

Pan Q, Chathery Y, Wu Y et al (2007a) Neuropilin-1 binds to VEGF121 and regulates endothelial cell migration and sprouting. J Biol Chem 282: 24049-24056

Pan Q, Shai O, Lee LJ et al (2008) Deep surveying of alternative splicing complexity in the human transcriptome by high-throughput sequencing. Nat Genet 40: 1413-1415

Peiris-Pages M, Harper SJ, Bates DO et al (2010) Balance of pro- versus anti-angiogenic splice isoforms of vascular endothelial growth factor as a regulator of neuroblastoma growth. J Pathol 222: 138-147

Perrin RM, Konopatskaya O, Qiu Y et al (2005) Diabetic retinopathy is associated with a switch in splicing from anti- to pro-angiogenic isoforms of vascular endothelial growth factor. Diabetologia 48: 2422-2427

Plouet J, Moro F, Bertagnolli S et al (1997) Extracellular cleavage of the vascular endothelial growth factor 189amino acid form by urokinase is required for its mitogenic effect. J Biol Chem 272: 13390-13396

Pritchard-Jones RO, Dunn DB, Qiu Y et al (2007) Expression of VEGF(xxx)b, the inhibitory isoforms of VEGF, in malignant melanoma. Br J Cancer 97: 223-230

Qiu Y, Hoareau-Aveilla C, Oltean S et al (2009) The anti-angiogenic isoforms of VEGF in health and disease. Biochem Soc Trans 37: 1207-1213

Ranpura V, Hapani S, Wu S (2011) Treatment-related mortality with bevacizumab in cancer patients: a metaanalysis. JAMA 305: 487-494

Rennel ES, Waine E, Guan H et al (2008) The endogenous anti-angiogenic VEGF isoform, VEGF165b inhibits human tumour growth in mice. Br J Cancer 98: 1250-1257

Rennel ES, Varey AH, Churchill AJ et al (2009) VEGF(121)b, a new member of the VEGF(xxx)b family of VEGF-A splice isoforms, inhibits neovascularisation and tumour growth in vivo. Br J Cancer 101: $1183-1193$

Roskoski R Jr (2007) Vascular endothelial growth factor (VEGF) signaling in tumor progression. Crit Rev Oncol Hematol 62: 179-213

Saito T, Takeda N, Amiya E et al (2013) VEGF-A induces its negative regulator, soluble form of VEGFR-1, by modulating its alternative splicing. FEBS Lett 587: 2179-2185 
Schutz FA, Je Y, Richards CJ et al (2012) Meta-analysis of randomized controlled trials for the incidence and risk of treatment-related mortality in patients with cancer treated with vascular endothelial growth factor tyrosine kinase inhibitors. J Clin Oncol 30: 871-877

Shi X, Zhao M, Xie WK et al (2013) Inhibition of neovascularization and expression shift of pro-/antiangiogenic vascular endothelial growth factor isoforms after intravitreal bevacizumab injection in oxygen-induced-retinopathy mouse model. Chin Med J (Engl) 126: 345-352

Soker S, Miao HQ, Nomi M et al (2002) VEGF165 mediates formation of complexes containing VEGFR-2 and neuropilin-1 that enhance VEGF165-receptor binding. J Cell Biochem 85: 357-368

Tayama M, Furuhata T, Inafuku Y et al (2011) Vascular endothelial growth factor 165b expression in stromal cells and colorectal cancer. World J Gastroenterol 17: 4867-4874

Tozer GM, Akerman S, Cross NA et al (2008) Blood vessel maturation and response to vascular-disrupting therapy in single vascular endothelial growth factor-A isoform-producing tumors. Cancer Res 68: 23012311

Varey AH, Rennel ES, Qiu Y et al (2008) VEGF 165 b, an antiangiogenic VEGF-A isoform, binds and inhibits bevacizumab treatment in experimental colorectal carcinoma: balance of pro- and antiangiogenic VEGF-A isoforms has implications for therapy. Br J Cancer 98: 1366-1379

Vincenti V, Cassano C, Rocchi M et al (1996) Assignment of the vascular endothelial growth factor gene to human chromosome 6p21.3. Circulation 93: 1493-1495

Vintonenko N, Pelaez-Garavito I, Buteau-Lozano H et al (2011) Overexpression of VEGF189 in breast cancer cells induces apoptosis via NRP1 under stress conditions. Cell Adh Migr 5: 332-343

Wang R, Crystal RG, Hackett NR et al (2009) Identification of an exonic splicing silencer in exon 6A of the human VEGF gene. BMC Mol Biol 10: 103-109

Woolard J, Wang WY, Bevan HS et al (2004) VEGF165b, an inhibitory vascular endothelial growth factor splice variant: mechanism of action, in vivo effect on angiogenesis and endogenous protein expression. Cancer Res 64: 7822-7835

Yuan A, Lin CY, Chou CH et al (2001) Functional and structural characteristics of tumor angiogenesis in lung cancers overexpressing different VEGF isoforms assessed by DCE- and SSCE-MRI. PLoS One 6: e16062

Zygalaki E, Kaklamanis L, Nikolaou NI et al (2008) Expression profile of total VEGF, VEGF splice variants and VEGF receptors in the myocardium and arterial vasculature of diabetic and non-diabetic patients with coronary artery disease. Clin Biochem 41: 82-87

Zygalaki E, Tsaroucha EG, Kaklamanis, L et al (2007) Quantitative real-time reverse transcription PCR study of the expression of vascular endothelial growth factor (VEGF) splice variants and VEGF receptors (VEGFR-1 and VEGFR-2) in non small cell lung cancer. Clin Chem 53: 1433-1439 
a

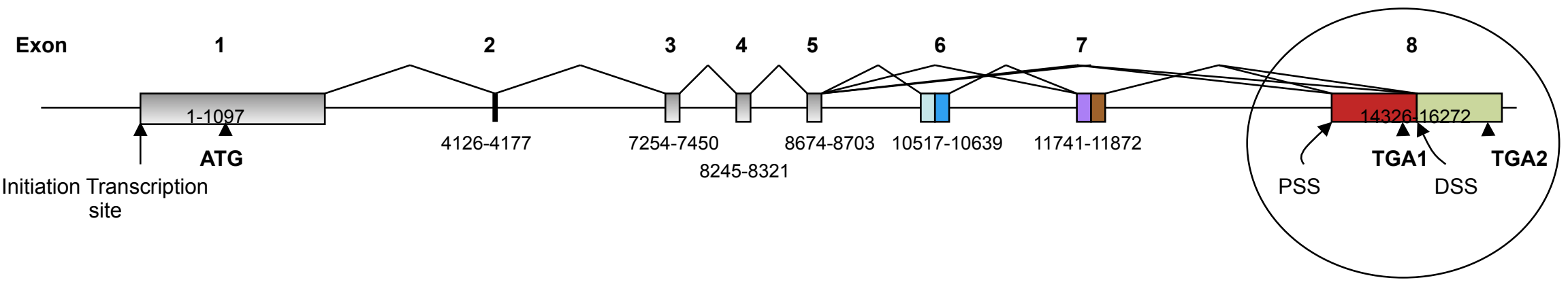

b

Exon 5/6/7 Proximal Splice Site

$8 a$

Distal Splice Site

$8 b$

ए

ACTTGCAGgttgg........tcagATGTGACAAGCCGAGGCGGTGAgccgggcaggaggaaggagcctccctcagggtttcgggaaccagATCTCTCACCAGGAAAGACTGAtacagaacg

\section{CDKPRR}

\section{SLTRKD}

C

Extracellular matrix affinity

of corresponding VEGF-A isoform

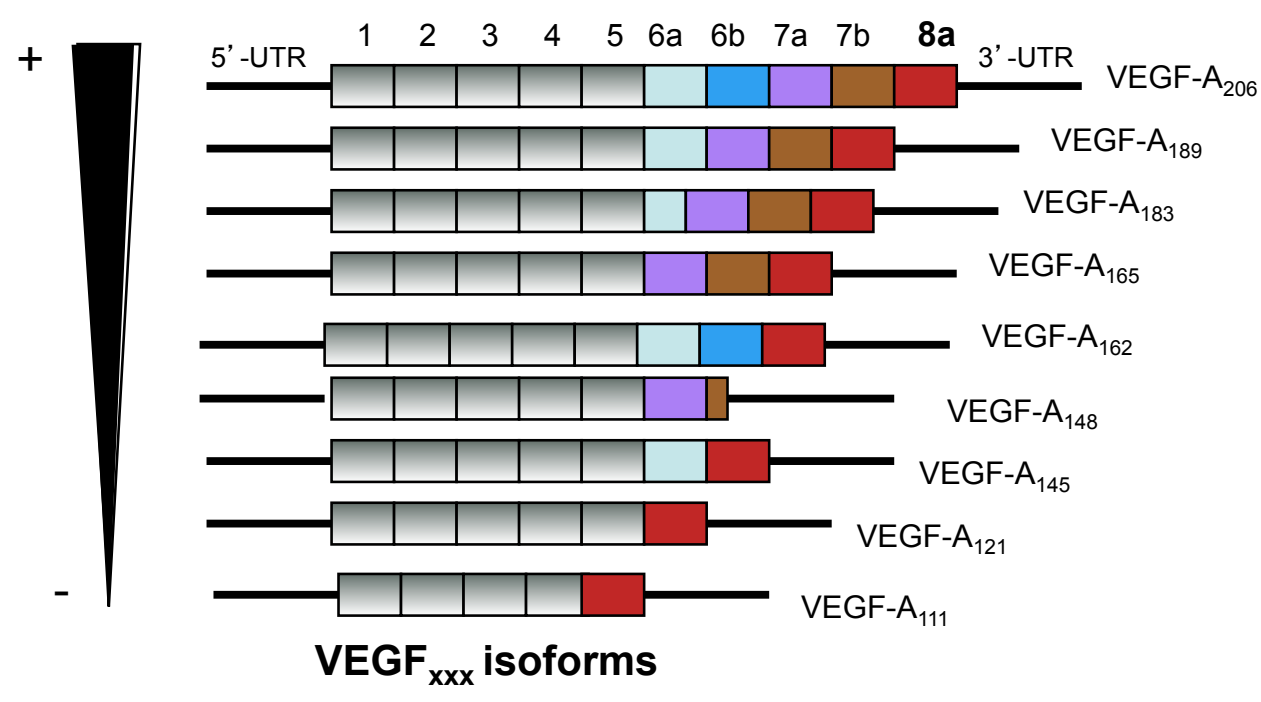

Pro-angiogenic family
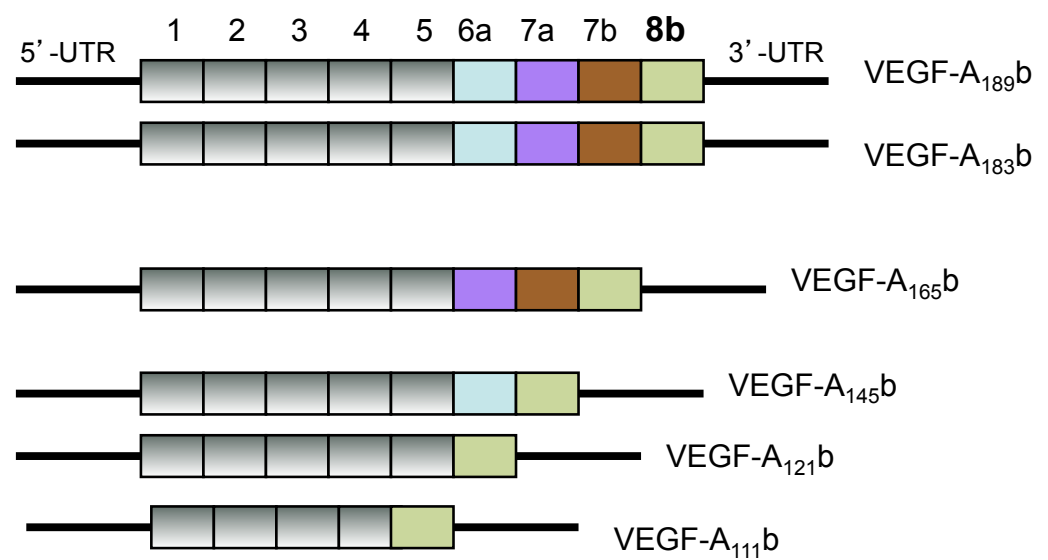

VEGF $_{x x x} b$ isoforms

Anti-angiogenic family 


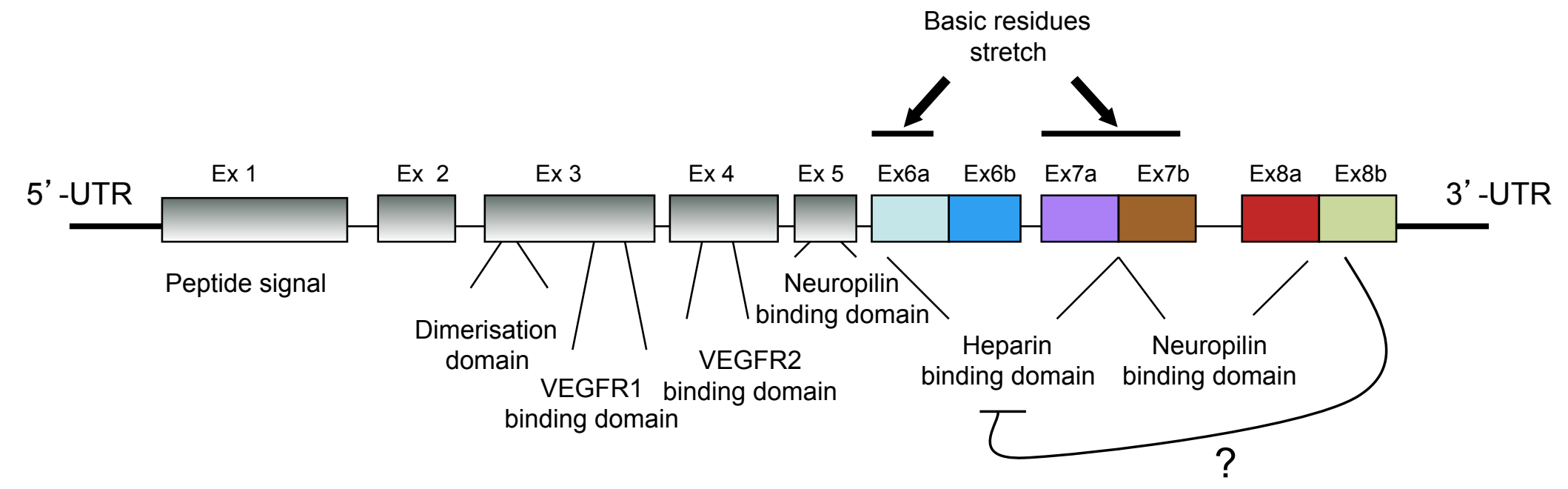


a
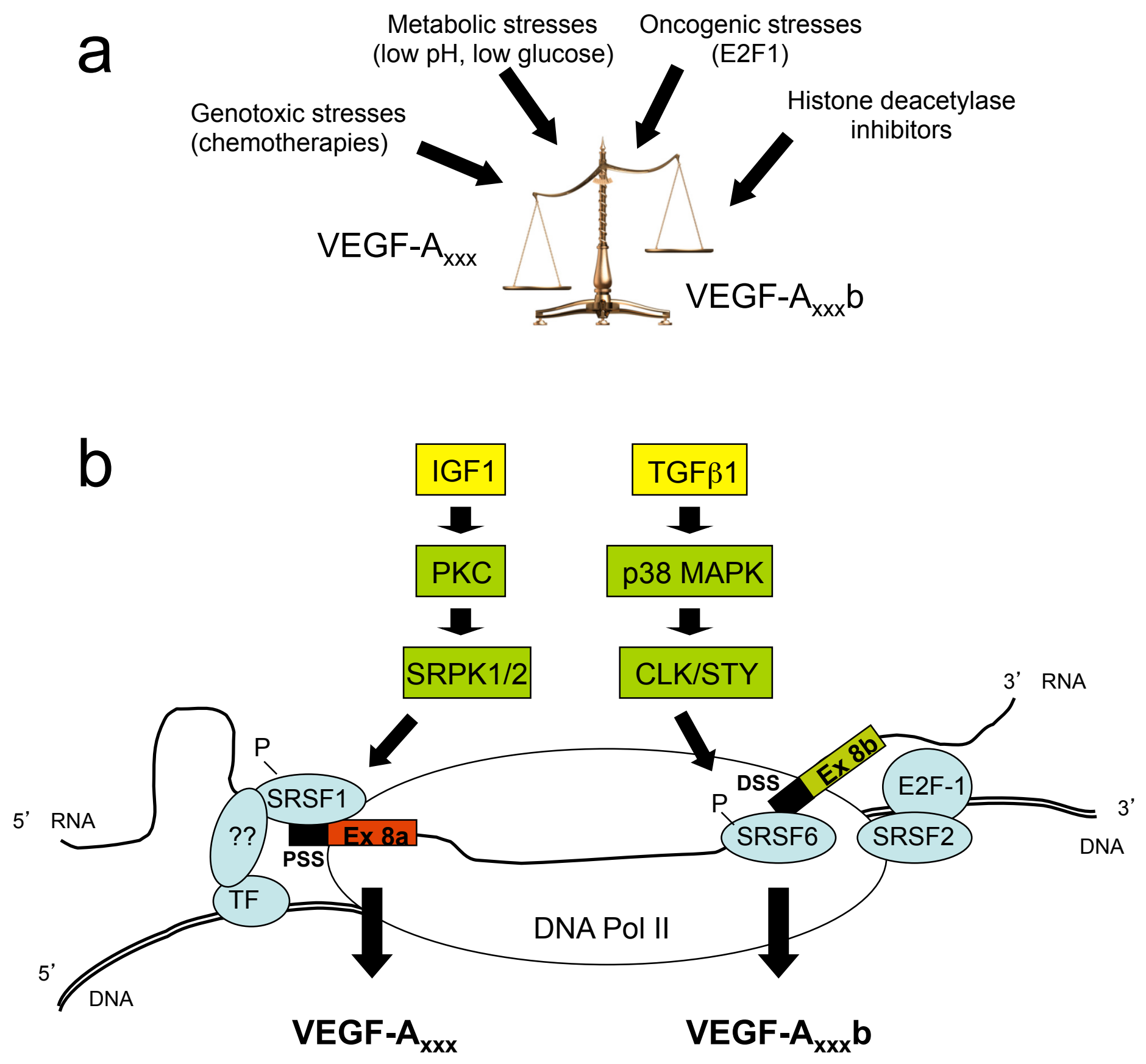


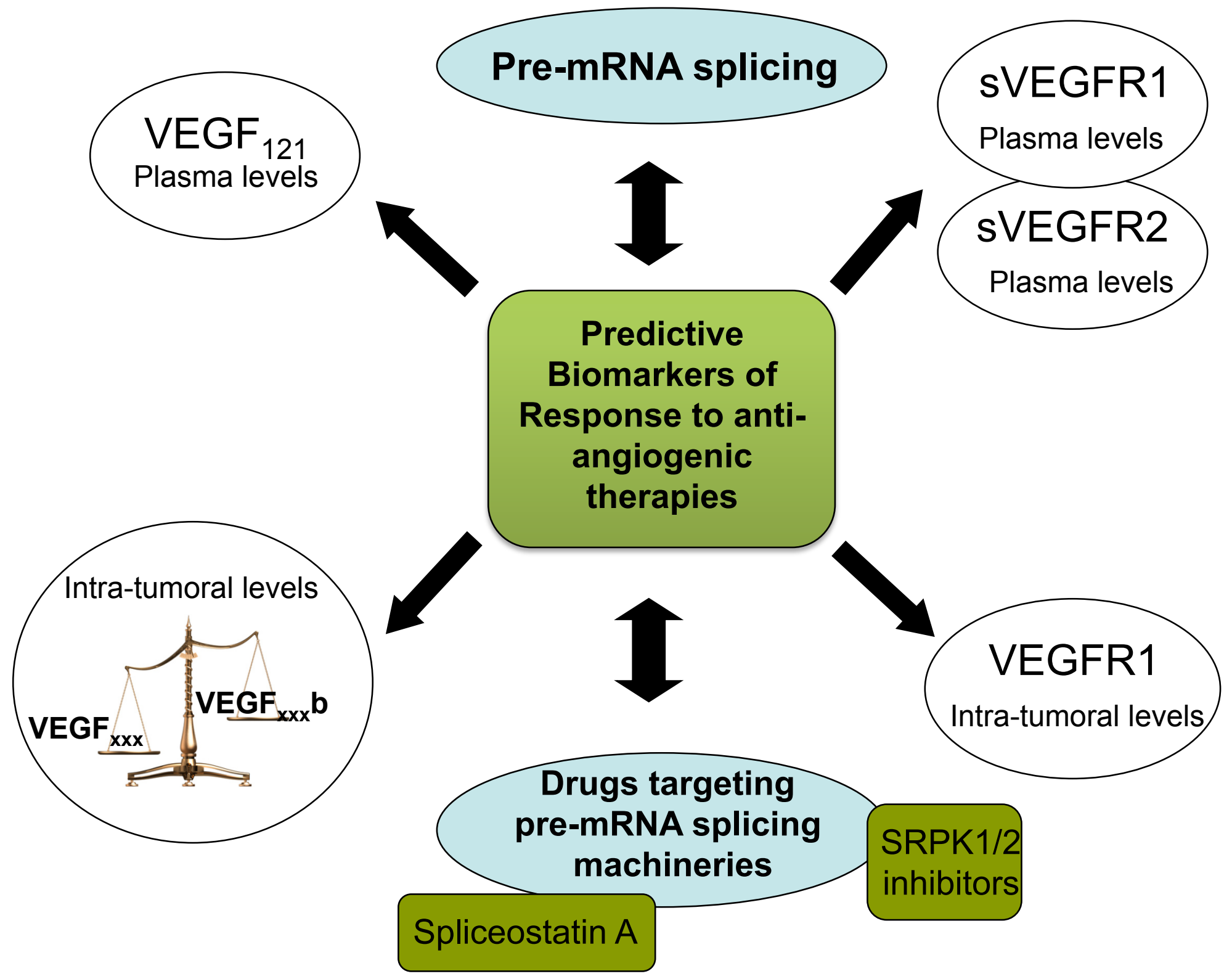

